\title{
The FLEX study school-based physical activity programs - measurement and evaluation of implementation
}

\author{
Catherine M. Wright ${ }^{1 *} \mathbb{D}_{\text {, }}$, Virginia R. Chomitz ${ }^{2 \dagger}$, Paula J. Duquesnay ${ }^{1}$, Sarah A. Amin ${ }^{3}$, Christina D. Economos ${ }^{1,4}$ \\ and Jennifer M. Sacheck ${ }^{5}$
}

\begin{abstract}
Background: Increasing children's physical activity (PA) at school is critical to obesity prevention and health promotion. Implementing novel, low-cost PA programs offers potential to contribute to children's in-school PA, particularly in resource-constrained schools. This evaluation describes implementation fidelity, reach, and dose of two PA programs in the Fueling Learning through Exercise (FLEX) Study.

Methods: Thirteen diverse, low-income Massachusetts elementary schools were recruited and randomized to the 100 Mile Club walking/running program $(n=7)$ or CHALKJJust Move classroom activity break PA program $(n=6)$. Intervention programs were delivered across two school years. Surveys with program champions/teachers and children, in-session measurement of children's PA by accelerometry (Actigraph GT3X) in a subset of schools, and key informant interviews were used to collect information on implementation, including fidelity, dose, reach, and sustainability, and to calculate an implementation score.

Results: Six CHALK/Just Move schools implemented the program in both years. Two schools randomized to 100 Mile Club did not implement at all, and only three schools implemented both years. Implementing schools had similar implementation scores (range $=0-3 ; 100$ Mile Club $=2.0$ vs. CHALKJJust Move $=1.9$ ) but fidelity to core and enhanced elements differed between programs. In 100 Mile Club schools, dose of program delivered was greater than in CHALK/Just Move schools (34.9 vs. 19.7 min per week). Dose of PA received per session was also greater in 100 Mile Club schools ( $n=55,2$ schools) compared with CHALK/Just Move schools ( $n=160,2$ schools) (13.6 min vs. 2.7 min per session). A slightly higher proportion of eligible children participated in CHALK/Just Move compared to 100 Mile Club (54.0\% vs. 31.2\%). Both programs were well received by champions/teachers and students.
\end{abstract}

Conclusions: Program implementation varied across programs and schools, and erosion in delivery was seen over the two years. However, among implementing schools, additional PA was delivered and received, and the programs were generally well-received. Although school resource issues remain barriers to implemention, this evaluation demonstrates that low-cost programs may enhance PA opportunities. Future research should evaluate how multiple programs can be implemented to increase children's PA at school.

Trial registration: ClinicalTrials.gov Identifier: NCT02810834. Registered May 11, 2015.

Keywords: Physical activity, Children, School-based intervention, Program evaluation

\footnotetext{
* Correspondence: catherine.wright@tufts.edu

${ }^{\dagger}$ Catherine M. Wright and Virginia R. Chomitz contributed equally to this work.

${ }^{1}$ Gerald J. and Dorothy R. Friedman School of Nutrition Science and Policy,

Tufts University, 150 Harrison Avenue, Boston, MA 02111, USA

Full list of author information is available at the end of the article
}

(c) The Author(s). 2019 Open Access This article is distributed under the terms of the Creative Commons Attribution 4.0 International License (http://creativecommons.org/licenses/by/4.0/), which permits unrestricted use, distribution, and reproduction in any medium, provided you give appropriate credit to the original author(s) and the source, provide a link to the Creative Commons license, and indicate if changes were made. The Creative Commons Public Domain Dedication waiver (http://creativecommons.org/publicdomain/zero/1.0/) applies to the data made available in this article, unless otherwise stated. 


\section{Background}

Physical activity (PA) plays a critical role in childhood obesity prevention in addition to conferring a number of other important health benefits [1-3]. However, fewer than half of all children in the U.S. meet the recommended $60 \mathrm{~min}$ of daily moderate-to-vigorous physical activity (MVPA) [4]. Schools are an ideal setting to provide opportunities to improve children's PA, given the amount of time they spend in school. Although guidelines recommend that schools provide at least 30 min of daily MVPA [5], competing demands, including a crowded school curriculum, focus on standardized tests, and constrained budgets, have limited PA programming in schools [6, 7].

Experts have recently called for a "whole school" approach to increasing children's PA [8], in which physical education (PE), recess, in-class PA breaks, and beforeand after-school programs collectively promote a healthy school environment. Evidence suggests that this may be even more critical for socioeconomically disadvantaged children who often accrue a greater proportion of their total daily PA at school [9]. In addition, environmental barriers, such as limited PA-supporting policies, activities, and infrastructure, have been observed in lower-socioeconomic status (SES) schools $[10,11]$, which can further constrain school-time PA opportunities and exacerbate disparities in PA. Nevertheless, even small increases in school-time MVPA may lead to the accumulation of additional daily PA and contribute positively to academic outcomes [12].

Novel strategies are needed to increase PA opportunities for children at school, particularly among low-SES children. Teacher-developed, champion-led school-based PA programs may have unique advantages with respect to acceptability, feasibility, and sustainability, compared to programs developed by researchers outside the school environment [13]. Documenting real-world implementation of these school-based PA programs is critical to understanding how they can be successfully sustained and scaled despite resource and time constraints and competing priorities.

This paper describes the implementation of two innovative school-based PA programs in the Fueling Learning through Exercise (FLEX) study [14], a cluster-randomized-controlled trial designed to evaluate

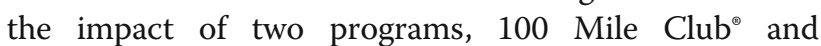
CHALK/Just Move ${ }^{\mathrm{T} w}$, on PA, cognition, and academic outcomes among elementary school children from low-income communities. The programs, identified through a nationwide contest, were developed by educators for use in schools and were selected for the trial based on their potential for scalability [15]. A primary aim of the FLEX Study was to evaluate the relative impact of these two programs on children's school-time and total daily MVPA. The evaluation presented here sought to quantify the extent to which the programs, which by design are different, were implemented in study schools, and help explain primary outcome results.

Using a mixed methods approach, we aimed to understand key elements of implementation, including program reach, dose, and fidelity by engaging direct implementers and participants. In addition, we sought to identify barriers to and facilitators of program delivery to inform opportunities for future dissemination.

\section{Methods}

\section{FLEX study design and program delivery}

Detailed methods for FLEX are described elsewhere [14]. Eighteen schools from eight lower-income communities in Massachusetts were recruited, either by assessing initial interest at the district level or directly with school administration, and block-randomized to the 100 Mile Club $(n=7)$, or CHALK/Just Move $(n=6)$, or control $(n=5)$. Randomization occurred after schools agreed to participate and to implement the program to which they were assigned. The interventions were delivered across two school years (2015-2016 and 2016-2017) for children in grades 3 through 5. One 100 Mile Club school opened the program to all grades. Programs were available to all children in participating grades/classrooms regardless of whether they were enrolled in the trial. Table 1 describes program characteristics and implementation according to randomization. The Institutional Review Board at Tufts University approved the study.

\section{Mile Club and CHALK/just move programs}

100 Mile Club [16] is a program that encourages children to walk, jog, or run 100 miles over the course of the school year (approximately 3 miles per week). The program can be implemented before, during, and/or after school, and is led by one or two school-wide champions (e.g., PE teacher, administrator, etc.) who log children's miles. Two core elements were central to the program: schools were asked to offer the program at least $30 \mathrm{~min}$ per week, which is sufficient for children to accrue 100 miles over the course of the school year, and to track mileage during sessions. Enhancements to promote participation included encouraging champions to display individual and school progress in a prominent location in the school, providing incentives at milestones (e.g. tee shirt at 25 miles), and holding special events (e.g. fun run, school-wide parade).

CHALK/Just Move [17] is a program of structured classroom-based PA breaks that combines high- and low-intensity movements (e.g. jumping jacks, squats, yoga poses) to provide PA for children while learning. CHALK/Just Move activities are presented on cards with 
Table 1 Description of PA program characteristics and implementation according to randomization

\begin{tabular}{|c|c|c|c|c|}
\hline & 100 Mile Club & Implementation & CHALKJJust Move & Implementation $^{a}$ \\
\hline $\begin{array}{l}\text { Underlying } \\
\text { philosophy/origin }\end{array}$ & $\begin{array}{l}\text { School-based walking/ } \\
\text { running program promoting } \\
\text { goal setting to encourage } \\
\text { students to walk/run } 100 \\
\text { miles over the school year. } \\
\text { Core elements: offer } \geq 30 \text { min } \\
\text { per week, track miles } \\
\text { Enhanced elements: display } \\
\text { mileage progress, offer } \\
\text { incentives, hold special event } \\
\text { (family fun-run, school-wide } \\
\text { event, etc.) }\end{array}$ & $\begin{array}{l}\text { Champions at schools } \\
\text { delivered any program } \\
\text { elements school-wide: } \\
\text { Year 1: 5/7 schools } \\
\text { Year 2: } 3 / 7 \text { schools }\end{array}$ & $\begin{array}{l}\text { Classroom-based physical } \\
\text { activity break program } \\
\text { incorporating high and low } \\
\text { intensity moves to be used } \\
\text { throughout the school day. } \\
\text { Core elements: offer daily } \\
\text { break of } \geq 5 \text { min, use activity } \\
\text { cards most or all of the time } \\
\text { Enhanced elements: integrate } \\
\text { breaks with academics, use } \\
\text { student leaders }\end{array}$ & $\begin{array}{l}\text { Classroom teachers at } \\
\text { schools delivered any } \\
\text { program elements: } \\
\text { Year 1: } 6 / 6 \text { schools (grades } 3 \& 4 \text { ) } \\
\text { Year 2: } 6 / 6 \text { schools (grades } 3 \& 4 \text { ) }\end{array}$ \\
\hline $\begin{array}{l}\text { All Training (content, } \\
\text { frequency, etc.) }\end{array}$ & $\begin{array}{l}\text { Annual } 30-40 \text { min training } \\
\text { offered to explain the } \\
\text { program, assist with mapping } \\
\text { routes, deliver program/ } \\
\text { tracking materials, bimonthly } \\
\text { check-ins via email }\end{array}$ & $\begin{array}{l}\text { Study staff provided training } \\
\text { at schools: Year } 1: 7 / 7 \text { schools } \\
\text { Year } 2: 3 / 7 \text { schools }\end{array}$ & $\begin{array}{l}\text { Annual } 10-20 \text { min training } \\
\text { offered to explain the } \\
\text { program and deliver program } \\
\text { guide and cards, bimonthly } \\
\text { check-ins via email with } \\
\text { newsletters to encourage } \\
\text { engagement and } \\
\text { implementation }\end{array}$ & $\begin{array}{l}\text { Study staff provided training } \\
\text { at schools: Year } 1: 36 / 38 \\
\text { teachers trained } \\
\text { Year 2: } 12 / 42 \text { teachers trained } \\
\text { (some trained both years) }\end{array}$ \\
\hline $\begin{array}{l}\text { Materials/supplies } \\
\text { provided }\end{array}$ & $\begin{array}{l}100 \text { Mile Club program } \\
\text { guide, clipboard box to assist } \\
\text { with tracking in field, tracking } \\
\text { posters, } 1000 \text { popsicle sticks } \\
\text { for tracking laps }\end{array}$ & $\begin{array}{l}\text { Study staff provided training } \\
\text { at schools: Year } 1: 7 / 7 \text { schools } \\
\text { Year 2: by request }\end{array}$ & $\begin{array}{l}\text { CHALKJJust Move program } \\
\text { guide and set of } 24 \text { activity } \\
\text { cards }\end{array}$ & $\begin{array}{l}\text { Study staff provided training } \\
\text { at schools: Year } 1: 38 / 38 \\
\text { Grade } 3 \& 4 \text { teachers } \\
\text { Year 2: } 19 / 19 \text { Grade } 5 \text { teachers; } \\
\text { 4th grade teachers by request }\end{array}$ \\
\hline
\end{tabular}

${ }^{a}$ CHALK/Just Move data were from all six randomized and implementing schools

pictures demonstrating movements and suggestions for connecting moves to academic subjects like math, English language arts, and science. Two core elements were essential to the program: classroom teachers were asked to use the cards during most or all sessions and offer at least one daily session of about $5 \mathrm{~min}$, which was determined to be feasible given teachers' busy schedules. Program enhancements designed to promote children's and teachers' engagement included integrating breaks with academic material (e.g. practicing multiplication through jumping jacks) and having students lead breaks.

\section{Champion and teacher training}

FLEX study staff trained champions, who were typically tapped by the principal, and classroom teachers to implement the programs in both study years. In 100 Mile Club schools, study staff offered a 30-40 min training at school at baseline (year 1) to explain the program, helped champions identify the best outdoor and indoor routes, and delivered printed program guides and other materials. At the start of year 2, study staff conducted check-ins via phone to re-engage champions, helped troubleshoot any barriers that surfaced during the first year, and offered support and/materials as needed. In CHALK/Just Move schools, study staff offered 10-20 min trainings annually to classroom teachers who would be implementing the program and delivered program guides and activity cards. Study staff provided support to champions and teachers throughout the two-year intervention, including regular check-ins via email. All schools received a $\$ 1000$ stipend to support their respective program.

\section{Intervention implementation evaluation methods}

The primary aims of the evaluation, informed by a process evaluation framework [18], were to document and quantify the quality and quantity of programming that schools delivered (implementation fidelity), to track the number of students who participated in the programs (reach), and to tally the average number of program minutes offered per week (dose delivered) and PA accrued in a given session (dose received). Program activities and activity benchmarks were specific to each individual program and by design were not intended to be equivalent. In addition, we sought to document receptivity to the programs, from the perspectives of both teachers/champions and students, as a measure of sustainability and scalability. Evaluation of the two programs could not be completely parallel due to differences in the structure and implementation of 100 Mile Club, a multi-grade program led by a single champion, and CHALK/Just Move, a classroom-based program. Analytic metrics are described for each evaluation measure in Table 2.

\section{Program surveys}

Champions and teachers were asked to complete brief online surveys at midpoint, to report details of year 1 implementation and post-intervention, to report details of year 2 implementation and plans for continuing 
Table 2 Description of measures used to assess PA program implementation

\begin{tabular}{|c|c|c|c|c|c|}
\hline Process measures & $\begin{array}{l}\text { Implementation } \\
\text { factor(s) measured }\end{array}$ & 100 Mile Club & $\begin{array}{l}\text { Collected/ } \\
\text { conducted }\end{array}$ & CHALK/Just Move & $\begin{array}{l}\text { Collected/ } \\
\text { Conducted }^{\mathrm{a}}\end{array}$ \\
\hline $\begin{array}{l}\text { Program surveys Teacher and } \\
\text { champion (web-based survey } \\
\text { link sent to all teachers \& } \\
\text { champions at each time } \\
\text { point) }\end{array}$ & $\begin{array}{l}\text { Implementation } \\
\text { and fidelity } \\
\text { Dose delivered } \\
\text { Reach } \\
\text { Receptivity and } \\
\text { sustainability }\end{array}$ & $\begin{array}{l}\text { Midpoint (Year 1), } \\
\text { Post-Intervention } \\
\text { (Year 2) }\end{array}$ & $\begin{array}{l}\text { Baseline: 6/7 } \\
\text { schools } \\
\text { Midpoint: 5/7 } \\
\text { schools } \\
\text { Post-intervention: } \\
\text { 3/7 schools }\end{array}$ & $\begin{array}{l}\text { Midpoint (Year 1), } \\
\text { Post-Intervention } \\
\text { (Year 2) }\end{array}$ & $\begin{array}{l}\text { Baseline: 16/57 } \\
\text { teachers/ } \\
\text { classrooms } \\
\text { Midpoint: } 6 / 23^{b} \\
\text { teachers/ } \\
\text { classrooms } \\
\text { Post-Intervention: } \\
\text { 20/57 teachers/ } \\
\text { classrooms }\end{array}$ \\
\hline $\begin{array}{l}\text { Child surveys Conducted at } \\
\text { post-intervention to assess } \\
\text { participation and reception of } \\
\text { program }\end{array}$ & Receptivity & $\begin{array}{l}\text { Post-Intervention } \\
\text { (Year 2) }\end{array}$ & $\begin{array}{l}\text { Post-intervention: } \\
\text { 5/7 schools }\end{array}$ & $\begin{array}{l}\text { Post-Intervention } \\
\text { (Year 2) }\end{array}$ & $\begin{array}{l}\text { Post-intervention: } \\
6 / 6 \text { schools }\end{array}$ \\
\hline $\begin{array}{l}\text { Accelerometry In-session } \\
\text { physical activity measurement }\end{array}$ & Dose received & $\begin{array}{l}\text { Physical activity } \\
\text { measured by } \\
\text { accelerometer; } \\
\text { start and end time } \\
\text { of session } \\
\text { recorded by } \\
\text { research staff }\end{array}$ & $\begin{array}{l}2 \text { implementing } \\
\text { schools }\end{array}$ & $\begin{array}{l}\text { Physical activity } \\
\text { measured by } \\
\text { accelerometer; } \\
\text { start and end time } \\
\text { of session(s) } \\
\text { recorded by } \\
\text { classroom } \\
\text { teachers }\end{array}$ & $\begin{array}{l}2 \text { implementing } \\
\text { schools, } 8 \\
\text { classrooms }\end{array}$ \\
\hline $\begin{array}{l}\text { Key informant interviews } \\
\text { Conducted with champions } \\
\text { and teachers after } \\
\text { post-intervention }\end{array}$ & $\begin{array}{l}\text { Implementation } \\
\text { and fidelity } \\
\text { Receptivity and } \\
\text { sustainability }\end{array}$ & $\begin{array}{l}20-30 \text { min } \\
\text { interviews } \\
\text { conducted via } \\
\text { telephone by } \\
\text { research staff }\end{array}$ & 4 champions & $\begin{array}{l}20-30 \text { min } \\
\text { interviews } \\
\text { conducted via } \\
\text { telephone by } \\
\text { research staff }\end{array}$ & $\begin{array}{l}14 \text { classroom } \\
\text { teachers }\end{array}$ \\
\hline
\end{tabular}

${ }^{a} \mathrm{CHALK} /$ Just Move data are from all six randomized and implementing schools

${ }^{\mathrm{b}}$ Only 4th grade teachers may have participated for two years and therefore were only ones asked to complete a survey at midpoint

programming). For 100 Mile Club schools, surveys included questions about scheduling of program sessions, numbers of participants, and methods for tracking and displaying mileage. For CHALK/Just Move schools, surveys included questions about the number and duration of daily breaks, use of activity cards, and integration of PA breaks with academic material. Champions and teachers were sent links to online surveys via email. Study staff sent reminders to non-responders.

\section{Child surveys}

Consented child participants randomized to 100 Mile Club or CHALK/Just Move were asked to complete a brief post-intervention survey to assess their participation in and feelings about the program. Questions asked children to report whether or not they participated in the program, whether they liked it, and whether they would participate again.

\section{In-session assessments}

In spring 2017, assessments were conducted in a subset of implementing schools to measure the time children spent engaging in PA during program sessions (dose received). All program schools were invited to participate. Prior to conducting assessments, research staff sent information letters home to parents explaining the evaluation and providing them the opportunity to "opt out" for their child. Likewise, children were given the opportunity to decline to wear an accelerometer prior to the start of assessments. Children who agreed were outfitted with waist-worn accelerometers (GT3x + and wGT3X-BT models, Actigraph LLC, Pensacola, FL) by trained study staff according to a standard protocol [14] [19]. In 100 Mile Club schools, children were outfitted with accelerometers at the beginning of sessions; study staff noted session start and end times. In CHALK/Just Move schools, children were outfitted with accelerometers at the beginning of the school day and teachers were asked to record start and end times of any breaks held that day on a form provided by and returned to research staff. Devices were collected at the end of sessions (100 Mile Club) and the end of the school day (CHALK/Just Move).

\section{Key informant interviews}

In Fall 2017, after completion of the study, semi-structured interviews with champions and teachers at schools randomized to either 100 Mile Club or CHALK/Just Move were conducted by telephone by a trained research assistant (see Additional files 1 and 2: Appendix for interview guides). Interviews were requested of all 100 Mile Club champions. In CHALK/Just Move schools, we initially contacted all fourth grade teachers as they were asked to implement the program both years. 
The $20-30$ min interviews were designed to expand on the quantitative surveys and contextualize those results by delving more deeply into specifics of how programs were implemented including scheduling and timing. We sought to document how programs were received, and factors related to program sustainability and scalability, including perceptions of which elements were most and least successful, challenges to implementation, and ideas on how programs could be improved to better engage teachers and children. Interviews were recorded and transcribed, and assessed for emergent themes. Those interviewed were provided a $\$ 35$ gift card for participation.

Intervention evaluation scoring development and analysis Intervention implementation was evaluated at two levels. The first level of the evaluation was aimed at identifying which schools randomized to 100 Mile Club or CHALK/ Just Move implemented the program at all (randomized cohort). This was based on study staff's direct contact with school staff and inquiries regarding PA program implementation. For the next evaluation level, implementation metrics were applied to schools that implemented any program elements during the first year of FLEX (implementation cohort); metrics assessed the two-year average fidelity and dose of the program and the maximum reach for either year for each program Descriptive analyses were used to summarize implementation results for both programs.

For the implementation cohort, data from champion and teacher surveys were extracted from Qualtrics and analyzed using Microsoft Excel. Implementation details and dose were reported for 100 Mile Club schools by champions. CHALK/Just Move implementation details and dose were reported by teachers and averaged across classrooms to create school-level metrics to parallel 100 Mile Club. Interview and observation data were used to supplement incomplete survey data.

\section{Implementation and fidelity}

We estimated the percentage of schools that offered core elements of the PA program over two years as well as the percentage of schools that offered any enhancements. An implementation score was created that ranged from 0 to 3 . This score is comprised of the sum of two separate scores: fidelity to core elements $(0-2)$ plus the use of enhanced program elements $(0-1)$. Schools could receive a score of 0 for not implementing at all, a score of 1 for not implementing core elements to standard, or a score of 2 for fully implementing both core required elements (reported as "most of the time" or "always" on surveys). A score of 0 was assigned if no enhancement was used at least "most of the time" and a score of 1 was given when at least 1 enhancement was used "most of the time" or "always." A key rationale for developing an overall implementation score was to have a metric to compare these two programs, however different, across the entire study to quantify delivery and explain primary outcomes discussed in separate manuscripts.

\section{Dose delivered}

Dose of programming delivered was defined as minutes per week per school. Champions and teachers were asked to report the minutes per week that they offered PA programming at midpoint (year 1) and post-intervention (year 2) as categorical responses. For 100 Mile Club, champions selected the response that reflected total minutes of PA programming offered each week across all sessions. Categories, in minutes, were $0-15,16-30,31-$ 45, 46-60, 61-75, 76+. CHALK/Just Move teachers were asked to report sessions offered per week and minutes per session. To estimate total PA minutes per week, the medians of the selected categorical response for each question were multiplied to determine an estimated PA program minutes per week. Responses for sessions per week were $0-2,3-4,5-6,7-8,9-11,12+$. Minutes per session responses were $0-2,3-4,5-6,7-8,9-10,11+$. For example, if a teacher reported 3-5 (median $=4)$ sessions per week and 7-8 (median $=7.5)$ minutes per session, then 30 min of weekly PA programming was estimated. If $12+$ sessions or $11+$ minutes were reported, 12 sessions and $11 \mathrm{~min}$ were used as there was no median value.

\section{Dose received}

Dose received was determined by average minutes children engaged in light PA (LPA) and MVPA in program sessions, measured by accelerometer, in the subset of participating schools. Accelerometer data were processed using a 15-s epoch to more accurately record short, intermittent bursts of activity common among children [20]. Data were categorized into minutes of sedentary, light, moderate, and vigorous activity using thresholds developed specifically for children [21], and analyzed using Stata/SE 14.0 (College Station, TX).

\section{Reach}

To measure program reach, information reported in champion and teacher surveys was used. 100 Mile Club champions reported the number of students regularly participating across all grades including those either eligible for or enrolled in FLEX during year 1 (grades 3 and 4) and year 2 (grades 4 and 5). For one 100 Mile Club school where participant numbers were not provided on the survey, session participation observed and documented by research staff was used. CHALK/ Just Move teachers reported whether their class was participating and the number of students in their class. 
Reach was calculated by dividing the number of participating students by the total number of students in the eligible grades. The number of students in each grade at each school was obatined from publicly available data from the Massachusetts Department of Education (DOE) [22]. Reach was calculated at each school for years 1 and 2 and the highest percentage from either year was used. This method was chosen because there was not a clear way to know if the same or different students were participating each year.

\section{Receptivity and sustainability}

To better understand program receptivity and potential for sustainability and scalability for future dissemination, as well as barriers to and facilitators of implementation, we evaluated champion/teacher and student attitudes toward the programs. For champions/teachers, we defined receptivity as the percent who indicated on surveys at the mid-point and post-intervention time point that they would implement their respective program again. Children's receptivity to the program was determined by both the percent of children who indicated on surveys that they liked the program and the percent of children who indicated that they would participate in the program again. Additional information on program sustainability was gathered from key informant interviews with champions and teachers from all schools randomized to the programs. Common as well as program-specific themes from the interviews were identified and refined by study staff familiar with program implementation.

\section{Results}

Demographic characteristics of the FLEX schools as randomized are presented in Table 3. These data were obtained from publicly available data from the DOE [22]. The schools randomized to 100 Mile Club and CHALK/Just Move are similar: more than half of the students are non-white $(62.6 \%$ non-white at 100 Mile Club schools; $58.9 \%$ non-white at CHALK/Just Move schools) and more than a third are from economically disadvantaged families [23] (39.2\% at 100 Mile Club; $45.0 \%$ at CHALK/Just Move schools). Demographic characteristics of schools that implemented 100 Mile Club were similar to the full randomized group, including two schools that did not implement the program.

Table 4 summarizes implementation metrics for all schools randomized to the FLEX programs (randomized cohort) and for schools that implemented the programs (implementation cohort). Figure 1 describes delivery in one school from each program with exemplary implementation, including core elements and enhancements.

\section{Randomized cohort}

Of the seven schools randomized to 100 Mile Club, five (71.4\%) schools in year 1 and three of these schools (42.9\%) in year 2 implemented the program to some extent. Two schools (28.6\%) did not implement the program either year. Six of six schools assigned to CHALK/ Just Move implemented the program to some extent in each of the two years.

\section{Implementation cohort}

The implementation cohort consists of the five 100 Mile Club schools and 26 classrooms from all six randomized CHALK/Just Move schools. Implementation metrics, reach, and dose, as well as teacher/champion and student receptivity to the programs, are presented in Table 4, and discussed in more detail below.

Table 3 Baseline characteristics of FLEX Schools

\begin{tabular}{|c|c|c|c|}
\hline & $\begin{array}{l}100 \text { Mile Club - randomized } \\
(N=7)\end{array}$ & $\begin{array}{l}100 \text { Mile Club - implemented } \\
(N=5)\end{array}$ & $\begin{array}{l}\text { CHALKJJust Move }^{a} \\
(N=6)\end{array}$ \\
\hline Eligible students per school (Mean, range) ${ }^{b}$ & $182(95-509)$ & $200(107-509)$ & $138(47-180)$ \\
\hline \multicolumn{4}{|l|}{ Race/ethnicity } \\
\hline$\%$ African-American & $19.1 \%$ & $19.9 \%$ & $8.3 \%$ \\
\hline$\%$ Asian & $9.9 \%$ & $10.8 \%$ & $6.5 \%$ \\
\hline$\%$ Hispanic & $28.4 \%$ & $22.3 \%$ & $40.7 \%$ \\
\hline$\%$ White & $37.2 \%$ & $41.3 \%$ & $41.1 \%$ \\
\hline$\%$ Multi-race & $5.1 \%$ & $5.6 \%$ & $3.3 \%$ \\
\hline$\%$ other & $0.1 \%$ & $0.1 \%$ & $0.1 \%$ \\
\hline$\%$ economically disadvantaged ${ }^{c}$ & $39.2 \%$ & $38.0 \%$ & $45.0 \%$ \\
\hline Per child school expenditures ${ }^{d}$ (mean, range) & $\$ 15,258(\$ 13,098-\$ 20,312)$ & $\$ 14,679(\$ 13,098-\$ 16,871)$ & $\$ 14,814(\$ 13,244-\$ 16,871)$ \\
\hline
\end{tabular}

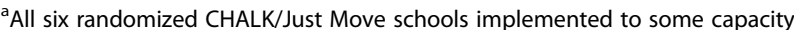

bEligibility for program participation was grade 3-5, with exception of one school that made program available to grades K-5

'Economically disadvantaged measure based on student's participation in the Supplemental Nutrition Assistance Program (SNAP), Transitional Assistance for Families with Dependent Children (TAFDC), Department of Children and Families' (DCF) foster care programs, and/or MassHealth (Medicaid)

${ }^{d}$ Data from 2016 
Table 4 Summary of school-level measures estimated over two years among FLEX PA program schools

\begin{tabular}{|c|c|c|}
\hline & 100 Mile Club & CHALKJJust Move \\
\hline Randomized cohort of FLEX schools: & $N=7$ & $N=6$ \\
\hline Any implementation Year 1 & $71.4 \%$ & $100 \%$ \\
\hline Any implementation Year 2 & $42.9 \%$ & $100 \%$ \\
\hline Implementation cohort of FLEX schools & $N=5$ & $N=6$ \\
\hline CHAMPIONS/TEACHERS & $n=5$ & $n=26$ \\
\hline \multicolumn{3}{|l|}{ Implementation } \\
\hline$\%$ of schools offering core PA program elements to standard & $40.0 \%$ & $19.2 \%$ \\
\hline$\%$ of schools offering any enhanced PA program elements & $60.0 \%$ & $65.4 \%$ \\
\hline Implementation score per school (mean, range) & $2.0(1.5-3)$ & $1.9(1.5-2.33)$ \\
\hline \multicolumn{3}{|l|}{ bose Delivered } \\
\hline PA program minutes offered per week per school (mean, range) & $34.9(23.0-45.5)$ & $19.7(11.1-39.4)$ \\
\hline${ }^{\mathrm{C}}$ Dose Received & $n=55$ students & $n=160$ students \\
\hline MVPA minutes (mean, SD) per session & $9.6(4.2)$ & $0.5(0.8)$ \\
\hline LPA minutes (mean, SD) per session & $4.0(3.0)$ & $2.3(1.7)$ \\
\hline Total PA minutes (mean, SD) per session & $13.6(5.0)$ & $2.7(2.2)$ \\
\hline Sedentary minutes (mean, SD) per session & $0.4(1.3)$ & $4.0(2.7)$ \\
\hline Average length of session in minutes (mean, range) & $25.0(20.0-30.0)$ & $6.2(3.0-11.0)$ \\
\hline \multicolumn{3}{|l|}{${ }^{d}$ Reach } \\
\hline$\%$ of students reached per participating school (range) & $31.2 \%(16.7-62.5 \%)$ & $54.0 \%(34.4-100 \%)$ \\
\hline Mean number of students reached per participating school & 59 & 67 \\
\hline${ }^{\mathrm{e}}$ Receptivity & $n=3$ & $n=19$ \\
\hline$\%$ of champions/teachers who indicated they would do program again & $66.7 \%$ & $89.5 \%$ \\
\hline STUDENTS & $n=285$ & $n=241$ \\
\hline \multicolumn{3}{|l|}{ Receptivity } \\
\hline$\%$ of students who indicated they liked the program & $72.7 \%$ & $69.2 \%$ \\
\hline$\%$ of students who indicated they would do it again & $80.8 \%$ & $91.6 \%$ \\
\hline
\end{tabular}

${ }^{a}$ Implementation Score $=$ Score (0-3) based on estimate of the extent to which essential and enhanced PA program elements were implemented to standard per school (see Table 1 for detail)

${ }^{\mathrm{b}}$ PA Program minutes offered per week = based on estimated number of minutes that students were exposed to PA program per week per school averaged across two years of implementation

PA Program minutes planned per week = based on estimated number of minutes that champions/teachers reported planning to offer of PA programming (at baseline prior to program start)

${ }^{c}$ Average minutes children engaged in MVPA during program session; 100 Mile Club represents 2 schools, CHALK/Just Move represents 8 classrooms from 2 schools ${ }^{\mathrm{d}}$ Reach = estimate based on maximum number of students exposed to the PA program per school per two years of implementation, estimate based on reported number of participants from surveys and for 1 school from direct observation

${ }^{\mathrm{e}}$ Champion/teacher receptivity: 100 Mile Club represents 3 schools, CHALK/Just Move represents 19 teachers from 5 schools

\section{Implementation and fidelity}

Schools implementing the programs had overall similar implementation scores (100 Mile Club $=2.0$ vs CHALK/ Just Move $=1.9$ ). However, fidelity to core and enhanced elements was different between the two programs. Champions at 100 Mile Club schools were somewhat more likely to report fidelity to core program elements (40.0\% of respondents) than were teachers in CHALK/ Just Move schools (19.2\% of the respondents). However, about $65 \%$ of CHALK/Just Move teachers (17 of 26) offered at least one program enhancement, compared with $60 \%$ of the 100 Mile Club respondents. One 100 Mile Club school implemented fully to standard, with both core and enhanced elements. By comparison, no CHALK/Just Move school implemented fully to standard.

\section{Dose delivered}

Champions in 100 Mile Club schools reported offering a higher dose of PA programming than did teachers in CHALK/Just Move schools. 100 Mile Club champions reported offering about $35 \mathrm{~min}$ per week. On average, 100 Mile Club schools held 3.4 sessions per week (data not shown). CHALK/Just Move teachers reported offering about $20 \mathrm{~min}$ per week per school. On average, across all CHALK/Just Move schools, teachers reported offering 3.6 sessions per week (data not shown). 


\begin{tabular}{|l|}
\hline 100 Mile Club - High-implementing school \\
Champion \\
- Young, energetic PE teacher \\
Core Elements \\
- Schedule 2 before-school sessions, $\geq 30$ \\
minutes of program time per session \\
- Tracking \\
- Used popsicle sticks for tracking laps \\
while walking \\
- Also used scanning system that allowed \\
for quicker lap tracking and exporting \\
mileage directly to database \\
Enhoncements \\
- Display mileage progress outside gymnasium \\
where children could see it \\
- Tee-shirt incentive for mileage milestone \\
Other factors \\
- 2 -3 parent volunteers to help with tracking \\
and encouragement during sessions
\end{tabular}

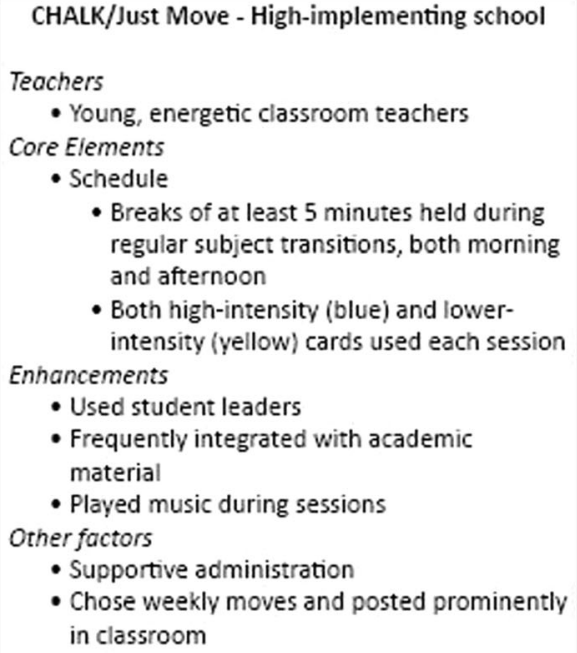

Fig. 1 Champion/teacher characteristics and elements of exemplary program delivery for 100 Mile Club and CHALK/Just Move

\section{Dose received}

100 Mile Club sessions were measured at two schools. In both cases sessions were held before school in a drop-in format where children joined as they arrived to school. Children $(n=55)$ from the two 100 Mile Club schools engaged in an average of $13.6 \mathrm{~min}(\mathrm{SD}=5.0)$ of PA per session. 100 Mile Club sessions were, on average, $25.0 \mathrm{~min}$ long (range: 20.0-30.0). In the two CHALK/Just Move schools, children $(n=160)$ from eight classrooms, engaged in an average of $2.7 \mathrm{~min}(\mathrm{SD}=2.2$ ) of PA per session, with an average of 1.5 sessions (range: $1-3$ ) per day. The average length of sessions was $6.2 \mathrm{~min}$ (range: 3.0-11.0). The impact of the programs on children's overall PA will be presented in a separate manuscript.

\section{Reach}

We estimated that the FLEX PA programs reached about one-third to half of all eligible students in participating schools at some point during the two years of implementation. A somewhat higher proportion and number of students participated in CHALK/Just Move (54.0\%; $n=67$ students per school) than 100 Mile Club (31.2\%; $n=59$ students per school).

\section{Receptivity, sustainability and scalability}

In post-intervention surveys, the majority of champions and teachers reported that they would do their assigned program again. However, nearly 90\% (17 out of 19) of CHALK/Just Move teachers, compared with 67\% (2 out of 3) of 100 Mile Club champions reported that they would do the program again. Among children who consented to take part in the trial and who participated in the programs, 100 Mile Club was received somewhat more favorably with $72.7 \%$ responding that they liked the program compared with $69.2 \%$ of children who said they liked CHALK/Just Move. Children participating in CHALK/Just Move reported being more likely to do the program again compared with those who participated in 100 Mile Club (91.6\% vs. $80.8 \%$ respectively).

Table 5 presents the results of post-intervention interviews with champions/teachers regarding program sustainability and scalability. Semi-structured interviews were conducted with champions from four 100 Mile Club schools, including one randomized, non-implementing school, and 14 CHALK/Just Move teachers, representing all six randomized and implementing schools. Champions at the three other 100 Mile Club schools did not respond to repeated interview requests. Interview participants generally expressed satisfaction with the programs. They highlighted the importance of PA for improving children's focus at school and/or overall academic performance, and saw potential in these programs for conferring these benefits.

Key themes specific to each program emerged from the interviews. Champions in 100 Mile Club schools indicated that before-school sessions were most successful and well attended, and a positive outcome of the program was that it promoted school community by facilitating interaction among children from multiple grades and encouraging participation of other school staff and/or parents, caregivers, and other family members. Teachers from CHALK/Just Move schools noted that the program was easy to integrate into the classroom and was often used as a transition between subjects. They also observed that integration of an online or video component could be beneficial, and having activity cards in additional 
Table $\mathbf{5}$ Lessons learned about receptivity and sustainability

\begin{tabular}{|c|c|c|}
\hline \multicolumn{3}{|l|}{ Common enabling factors across programs } \\
\hline Adequate time available & Administration buy-in and support & Enthusiasm from implementer \\
\hline Program specific enablers and barriers & 100 Mile Club & CHALK/Just Move \\
\hline \multirow[t]{6}{*}{ Enablers } & - Adequate outdoor/indoor routes & - Easy to use \\
\hline & - Highly engaged school champion and staff & - Highly adaptable to class schedule \\
\hline & - Delegation of tracking & - Flexibility with high and low intensity moves \\
\hline & & - Visual cues of cards helpful \\
\hline & & - Teachers sharing tips between themselves \\
\hline & & - Useful for classroom/subject transitions \\
\hline \multirow[t]{5}{*}{ Barriers } & $\begin{array}{l}\text { - Challenges making indoor route feasible } \\
\text { and fun }\end{array}$ & - Physical cards can get lost \\
\hline & - Conflicts with the school schedule-recess or PE & - Lack of language translation \\
\hline & - Maintaining tracking & - Physical size of classroom for certain exercises \\
\hline & $\begin{array}{l}\text { - Responsibility for keeping program going falls } \\
\text { mainly to one person }\end{array}$ & - Engagement of teachers and students \\
\hline & & - Lack or insufficient initial and ongoing training \\
\hline Recommendations for future implementation & 100 Mile Club & CHALKJJust Move \\
\hline Sustainability & & - More teacher training and/or check-ins \\
\hline \multirow[t]{2}{*}{ Scalability } & - Define it as a school-wide program & - Translation to encourage ELL/ESL student leaders \\
\hline & - Help schools enhance indoor routes & - Creation of cards with moves for older grades \\
\hline
\end{tabular}

languages would help engage students whose first language is not English.

\section{Discussion}

This evaluation was conducted to describe the extent to which two school-based PA programs designed to increase student's access to PA in school were implemented in FLEX, and to understand key factors associated with implementation that could inform future dissemination of the programs. The 100 Mile Club and CHALK/Just Move programs were identified through a nationwide crowdsourcing competition for their potential for scalability, including cost-effectiveness and flexibility [15] and determined to hold promise as low-cost, non-resource-intensive PA programs that may be suitable for lower-income, racially and ethnically diverse communities. The FLEX research design emphasized a real-world implementation, in which participating schools were not expected to allocate money to the programs, though they did require human capital and a suitable physical environment. Schools were assigned to PA programs based on the study randomization, rather than on their enthusiasm for implementing a specific program.

Results from this evaluation indicate that among our sample of diverse, low-to-moderate income schools that even when provided external resources and support to implement these programs, not all schools can or will do so. Among the seven schools randomized to 100 Mile
Club, over a quarter of the schools did not implement the program at all, and among those that did there was erosion over the two years from 5 to 3 schools. Only one 100 Mile Club school champion implemented fully to standard and included enhancements in both years, like displaying children's mileage progress outside the gym where they and others could see it, and recruiting parent volunteers (2-3 per session) to help with tracking and provide encouragement to the children during 100 Mile Club sessions (Fig. 1). Together, these types of factors likely worked to build children's enthusiasm for and participation in the program.

In the case of CHALK/Just Move, all randomized schools implemented the program to some extent, but only $19 \%$ of classrooms did so to standard. In the example of the high-implementing CHALK/Just Move school (Fig. 1), teachers held daily breaks in both the morning and afternoon, regularly using them as transitions between subjects, and typically incorporated both high- and low-intensity moves. Sessions were enhanced by regularly choosing students to lead the breaks and by integrating them with academic material. While CHALK/Just Move may have been easier to implement overall, particularly as it did not rely on a single champion, not all teachers adopted to the same level and may not have sustained the same level of engagement throughout the school year.

While our ability to understand all implementation factors was limited by the relatively small number of 
respondents, it was clear that the programs were delivered inconsistently. The year-to-year erosion seen among the 100 Mile Club schools might suggest that though the program may have been relatively easy to implement initially, over time it proved challenging to sustain. Because the program typically relied on a single champion, the success of the program was driven by how engaged that champion was. Where it worked, it worked well, but this was not equally true for all schools. In addition, the school physical environment, in particular having adequate and accessible outdoor space, was key to successful and sustained implementation of 100 Mile Club. This may be especially relevant to urban and resource-strapped schools that have limited facilities available.

Despite the mixed results of implementation, among schools that implemented the programs, there was a reported additional dose of total school PA minutes delivered and received per week. This reported dose delivered was higher among 100 Mile Club schools $(\sim 35$ min per week) than CHALK/Just Move schools $(\sim 20$ min per week). Likewise, the measured average total PA dose received per session was higher in 100 Mile Club compared with CHALK/Just Move (13.6 vs. $2.8 \mathrm{~min}$, respectively). This per session finding should be interpreted cautiously, since CHALK/Just Move sessions were delivered up to three times per day and up to five days per week, whereas 100 Mile Club sessions were usually delivered once per day and up to three times per week. Nevertheless, these findings suggest that both programs provided additional weekly PA minutes. Both programs were generally liked by the champions and teachers implementing the programs and by the children participating in them.

By design the FLEX Study was framed to evaluate two distinct PA programs chosen for their flexibility and adaptability to a range of school settings. The 100 Mile Club is a school-level, voluntary program typically held before school, while CHALK/Just Move is designed to be classroom-based. As a result, the two programs had differing reach in terms of number of children and, potentially, differences in participants by sex, weight status, and/or fitness. Unfortunately, we were not able to collect detailed information on all participating children. While the 100 Mile Club relied on a single champion to implement and maintain, responsibility for delivering CHALK/Just Move was spread across multiple teachers. Our evaluation found that because 100 Mile Club typically relied on one person to implement, champions were more likely to have either fully implemented or not implemented the program according to protocol; CHALK/Just Move had more teachers involved, but delivery of program elements was less uniform. As a result, the programs were offered in different ways across schools, and it was difficult to capture perfectly parallel implementation information for the two programs. Nevertheless, we collected enough similar information that we were able to compare and contrast the two programs. Inherent differences in the programs may therefore make one or the other more suitable to particular school environments or allow them to complement each other if implemented in tandem.

\section{Strengths and limitations}

A key strength of this evaluation of the real-world implementation of the PA programs is that it was included as part of a large, randomized controlled trial. This allowed for collection of program implementation data from a range of school environments and, in the case of child survey data, from a large sample of participants.

Another strength of the FLEX evaluation is that the intervention programs were developed by schools and teachers and because participating schools were randomized to either 100 Mile Club or CHALK/Just Move, we were able to evaluate delivery of the programs in a quasi-real world setting. This is notable because though we assume that the schools that agreed to participate had at least some willingness to implement a new PA program, they were randomly assigned to the program, rather than choosing the one that might best fit their school environment or culture. The fact that schools were randomized to the programs allowed for opportunities to understand school- and champion/teacher-level factors that influenced delivery and may be critical for sustainability and scalability.

Additionally, a strength of this evaluation is the mixed methods approach. The use of both quantitative and qualitative methods allowed for a more detailed examination of the various aspects of implementation. Multiple dimensions of process evaluation were used at multiple time points during the study.

A limitation of this evaluation is that the sample of champion and teacher respondents to surveys and interviews was limited and did not capture demographic characteristics of the respondents themselves (i.e. age, years teaching, personal PA/fitness status). That information may be valuable in understanding how to develop champions in the future for these kinds of interventions [24]. Further, though the teachers and champions were the implementers and therefore in a strong position to report on what happened in the programs, there may have been response bias. This includes limited data from non-implementing schools and classrooms. Nevertheless, in these kinds of real-world studies, we must balance the needs of collecting all key study data with limiting the burden on schools and teachers on whom we rely to collect those data. Researchers must weigh the importance of collecting primary outcome data against the need to collect process data to better understand those outcomes. In 
addition, while direct observation of programming by researchers may afford collection of more objective data, the presence of researchers may also influence the dynamics of implementation.

In addition, though accelerometry provided an objective measure of in-session PA, the waist-worn device may not be sufficiently sensitive to record many of the CHALK/ Just Move activities, particularly semi-stationary movements like stretches and yoga poses. Though schools that agreed to participate in the accelerometry sub-study were not necessarily representative of all schools, the sample was small, and data collected only one time, they did represent a range of implementation scores. Nevertheless, these data provide a picture of how much and what types of activity children engage in during the programs. In addition, by being integrated into the classroom setting, CHALK/Just Move may provide benefits beyond additional minutes of MVPA. Forthcoming analyses as part of FLEX will look at the impact of both programs on other aspects of children's overall health and well-being, including cognitive function and academic achievement.

\section{Conclusions}

The primary aim of the FLEX Study was to evaluate the impact of two different school-based PA programs on children's PA and to explore their feasibility for dissemination and scalability, particularly for resource-constrained schools. This evaluation demonstrates that overall both programs were overall well received by schools, including both champions/teachers and students. Some schools were able to implement the programs with minimal resources and without extensive support from researchers, particularly in the first year. However, schools may need additional financial and human capital investment and/or policy support to promote long-term sustainability. Researchers must be cognizant of the fact that schools, with finite resources, are by necessity making tradeoffs in choosing to implement one program or another. The results of this evaluation suggest that both programs, if implemented, can enhance opportunities for PA at school. The 100 Mile Club shows potential for providing meaningful increased PA minutes for children, but may have limited reach as a voluntary, before-school program and the burden for implementation falls to one champion. CHALK/Just Move, as a classroom-based program, has the potential to reach a large number of children, with the burden for delivery spread across multiple teachers, but likely offers more limited benefits in terms of MVPA. Identifying the program or programs that best fit individual schools is necessary for securing the buy-in critical to their success. Future work should evaluate how multiple PA programs can be put in place in schools simultaneously to increase children's opportunities for PA throughout the school day.

\section{Additional files}

Additional file 1: FLEX Key Informant Interview Guide - 100 Mile Club. Key informant interview objective and guide for FLEX Study 100 Mile Club schools. (DOCX $18 \mathrm{~kb}$ )

Additional file 2: FLEX Key Informant Interview Guide - CHALK/Just Move. Key informant interview objective and guide for FLEX Study CHALKJJust Move schools. (DOCX $21 \mathrm{~kb}$ )

\section{Abbreviations}

DOE: Department of Education; FLEX: Fueling Learning through Exercise; LPA: Light physical activity; MVPA: Moderate to vigorous physical activity; PA: Physical activity; PE: Physical education; SES: Socioeconomic status

\section{Acknowledgments}

The authors acknowledge Natalie Nesler, MS, for her contributions to this project. In addition, the authors wish to thank the schools, children, teachers, and other school staff who participated in the FLEX Study. Finally, for their collaboration on the intervention programs we thank Kara Lubin, founder of the 100 Mile Club, and Dr. Dodi Meyer and Dr. John Rausch of CHALKJJust Move at Columbia University/New York Presbyterian.

\section{Funding}

The FLEX Study is funded by the Eunice Kennedy Shriver National Institute of Child Health \& Human Development of the National Institutes of Health, Award Number R01HD080180. Additional funding was provided by the Boston Foundation. The content is solely the responsibility of the authors and does not necessarily represent the official views of the National Institutes of Health or the Boston Foundation. Neither of the funders had a role in the design of the study or the writing of this manuscript, nor did they have a role in data collection, analysis, or interpretation of data.

\section{Availability of data and materials}

The datasets used and/or analysed during the current study are available from the corresponding author on reasonable request.

\section{Authors' contributions}

CMW and VRC contributed equally to this manuscript. CMW, PJD, and SAA carried out analyses and CMW, VRC, PJD, and SAA drafted the manuscript. JMS, VRC, and CDE designed the FLEX study and received project grants. All authors critically reviewed and revised the final version of the manuscript. All authors have read and approved the final manuscript.

\section{Ethics approval and consent to participate}

This study was approved by the Institutional Review Board at Tufts University and registered at https://clinicaltrials.gov/ct2/show/NCT02810834 (Identifier: NCT02810834) prior to participant enrollment. Parents provided written consent for children to participate.

Consent for publication

Not applicable.

\section{Competing interests}

The authors declare they have no competing interests.

\section{Publisher's Note}

Springer Nature remains neutral with regard to jurisdictional claims in published maps and institutional affiliations.

\section{Author details}

${ }^{1}$ Gerald J. and Dorothy R. Friedman School of Nutrition Science and Policy, Tufts University, 150 Harrison Avenue, Boston, MA 02111, USA. ${ }^{2}$ Department of Public Health and Community Medicine, Tufts University School of Medicine, 136 Harrison Avenue, Boston, MA 02111, USA. ${ }^{3}$ Department of Nutrition and Food Sciences, University of Rhode Island, 125 Fogarty Hall, Kingston, RI 02881, USA. ${ }^{4}$ ChildObesity 180, Tufts University, Boston, MA 02111, USA. ${ }^{5}$ Department of Exercise and Nutrition Sciences, Milken Institute School of Public Health, The George Washington University, 950 New Hampshire Avenue, Washington, DC 20052, USA. 
Received: 15 August 2018 Accepted: 17 December 2018

Published online: 16 January 2019

\section{References}

1. Andersen LB, Riddoch C, Kriemler S, Hills A. Physical activity and cardiovascular risk factors in children. Br J Sports Med. 2011. https://doi.org/ 10.1136/bjsports-2011-090333.

2. Janssen I, LeBlanc AG. Systematic review of the health benefits of physical activity and fitness in school-aged children and youth. Int J Behav Nutr Phys Act. 2010;7:40

3. Kriemler S, Zahner L, Schindler C, Meyer U, Hartmann T, Hebestreit $H$, et al. Effect of school based physical activity programme (KISS) on fitness and adiposity in primary schoolchildren: cluster randomised controlled trial. Br Med J. 2010;340:c785.

4. Troiano RP, Berrigan D, Dodd KW, Mâsse LC, Tilert T, McDowell M. Physical activity in the United States measured by accelerometer. Med Sci Sports Exerc. 2008;40:181-8.

5. Kraak VA, Liverman CT, Koplan JP. Preventing childhood obesity: health in the balance. Washington, D.C.: National Academies Press; 2005.

6. Lounsbery MA, McKenzie TL, Trost S, Smith NJ. Facilitators and barriers to adopting evidence-based physical education in elementary schools. J Phys Act Health. 2011:8(Suppl 1):17-25.

7. Cox L, Berends V, Sallis JF, John JMS, McNeil B, Gonzalez M, et al. Engaging school governance leaders to influence physical activity policies. J Phys Act Health. 2011;8(Suppl 1):40-8.

8. Kohl HW III, Cook HD. Educating the student body: taking physical activity and physical education to school. Washington, D.C.: National Academies Press; 2013.

9. $\quad$ Singh A, Uijtdewilligen L, Twisk JW, Van Mechelen W, Chinapaw MJ. Physical activity and performance at school: a systematic review of the literature including a methodological quality assessment. Arch Pediatr Adolesc Med. 2012;166:49-55.

10. McCullick BA, Baker T, Tomporowski PD, Templin TJ, Lux K, Isaac T. An analysis of state physical education policies. J Teach Phys Educ. 2012;31:200-10.

11. Carlson JA, Mignano AM, Norman GJ, McKenzie TL, Kerr J, Arredondo EM, et al. Socioeconomic disparities in elementary school practices and children's physical activity during school. Am J Health Promot. 2014;28(Suppl):47-53.

12. Barr-Anderson DJ, AuYoung M, Whitt-Glover MC, Glenn BA, Yancey AK. Integration of short bouts of physical activity into organizational routine: a systematic review of the literature. Am J Prev Med. 2011;40(1):76-93.

13. Franks A, Kelder S, Dino GA, Horn KA, Gortmaker SL, Wiecha JL, et al. School-based programs: lessons learned from CATCH, planet health, and not-on-tobacco. Prev Chronic Dis. 2007:4(2):A33.

14. Wright CM, Duquesnay PJ, Anzman-Frasca S, Chomitz VR, Chui K, Economos $C D$, et al. Study protocol: the fueling learning through exercise (FLEX) study-a randomized controlled trial of the impact of school-based physical activity programs on children's physical activity, cognitive function, and academic achievement. BMC Public Health. 2016;16:1078.

15. Hatfield DP, Lynskey VM, Economos CD, Nichols ER, Whitman NB, Nelson ME. Crowdsourcing innovative physical activity programs: active schools acceleration project case study. Transl J Am Coll Sports Med. 2016;1:1-9.

16. 100 Mile Club Program. [cited 2018 Jul 19]. Available from: https:// 100mileclub.com/welcome/. Accessed 19 July 2018.

17. CHALKJJust Move Program. [cited 2018 Jul 19]. Available from: https://www. nyp.org/clinical-services/ambulatory-care-network-programs/chalk-choosinghealthy-and-active-lifestyles-for-kids/chalk-in-the-school. Accessed 19 July 2018

18. Rossi PH, Lipsey MW. Freeman HE. Evaluation: A Systematic Approach. Sage publications; 2003

19. Puyau MR, Adolph AL, Vohra FA, Butte NF. Validation and calibration of physical activity monitors in children. Obes Res. 2002;10:150-7.

20. Cain KL, Sallis JF, Conway TL, Van Dyck D, Calhoon L. Using accelerometers in youth physical activity studies: a reivew of methods. J Phys Act Health. 2013:43(4):437-50

21. Evenson KR, Catellier DJ, Gill K, Ondrak KS, McMurray RG. Calibration of two objective measures of physical activity for children. J Sport Sci. 2008;26(14):1557-65
22. Massachusetts Department of Education School and District Profiles . [cited 2018 Jul 19]. Available from: http://profiles.doe.mass.edu/. Accessed 19 July 2018.

23. Massachusetts Department of Elementary and Secondary Education. Redefining Low Income: A New Metric for K-12 Education. [cited 2018 Jul 19]. Available from: http://www.doe.mass.edu/infoservices/ data/ed.html. Accessed 19 July 2018.

24. Mâsse LC, McKay H, Valente M, Brant R, Naylor P-J. Physical activity implementation in schools: a 4-year follow-up. Am J Prev Med. 2012;43:369-77.
Ready to submit your research? Choose BMC and benefit from:

- fast, convenient online submission

- thorough peer review by experienced researchers in your field

- rapid publication on acceptance

- support for research data, including large and complex data types

- gold Open Access which fosters wider collaboration and increased citations

- maximum visibility for your research: over $100 \mathrm{M}$ website views per year

At $\mathrm{BMC}$, research is always in progress.

Learn more biomedcentral.com/submissions 